\title{
Полупроводниковые структуры с одномерным квантовым каналом и планарными боковыми затворами, созданные методом импульсной силовой нанолитографии
}

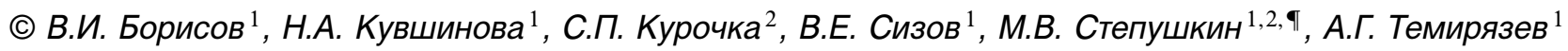 \\ ${ }^{1}$ Фрязинский филиал Института радиотехники и электроники им. В.А. Котельникова Российской академии наук, \\ 141190 Фрязино, Московская обл., Россия \\ ${ }^{2}$ Национальный исследовательский технологический университет „МИСиС“, \\ 119049 Москва, Россия \\ IE-mail: vbi@ms.ire.rssi.ru
}

(Получена 27 апреля 2017 г. Принята к печати 12 мая 2017 г.)

\begin{abstract}
Квазиодномерные полупроводниковые структуры с изменяемым продольным потенциальным рельефом созданы методом импульсной силовой нанолитографии, выполняемой с использованием атомно-силового микроскопа. Структуры изготавливались на основе гетероструктур $\mathrm{AlGaAs} / \mathrm{GaAs}$ с глубоким (130 нм от поверхности) залеганием двумерного электронного газа. Потенциальный профиль канала формировался с помощью секционированных планарных затворов, созданных по обеим сторонам канала. Электрические параметры полученных структур, измеренные при температурах до $1.5 \mathrm{~K}$, подтвердили эффективность примененного метода для создания изолирующих областей с латеральными размерами $\sim 10$ нм.
\end{abstract}

DOI: 10.21883/FTP.2017.11.45106.20

По мере приближения размеров твердотельных структур к нанометровой области все больше проявляются квантовые свойства электрона. С одной стороны, это приводит к нарушению работоспособности классических транзисторов, использующих закономерности поведения электрона как классической частицы, а с другой - открывает перспективы создания новых уникальных переключающих, запоминающих и усиливающих элементов для информационных систем. В основе их работы лежат квантоворазмерные эффекты, и для кодирования информации нужно иметь возможность управлять переносом электронов в таких элементах.

Создание и исследование одномерных и нуль-мерных наноструктур является одним из наиболее широко представленных в литературе направлений исследований в области теоретической и экспериментальной физики. Наиболее отработанным и широко используемым полупроводниковым материалом является кремний. На его основе создаются, в том числе и в промышленных масштабах, полупроводниковые структуры с нанометровыми размерами проводящих каналов. Однако уникальные транспортные характеристики двумерного электронного газа, формирующегося вблизи границы раздела в гетероструктурах $\mathrm{A}^{\mathrm{III}} \mathrm{B}^{\mathrm{V}}$, таковы, что на сегодняшний день именно они наиболее широко используются для создания наноструктур, предназначенных для исследования квантово-размерных эффектов. Наибольшее распространение в настоящий момент получили структуры $\mathrm{GaAs} / \mathrm{Al}_{x} \mathrm{Ga}_{1-x} \mathrm{As}$ (см., например, обзор [1]). Высокое совершенство кристаллической структуры, разработанные современные процессы технологической обработки таких структур позволяют создавать на их основе однои нуль-мерные структуры, транспортные характеристики которых при низких температурах определяются взаимодействиями носителей заряда [2,3].
При создании одномерных и нуль-мерных структур на основе полупроводниковых эпитаксиальных структур с двумерным электронным газом в основном используются два способа формирования ограниченной в размерах проводящей области: метод расщепленного затвора (split gate) и метод боковых управляющих затворов (in plane gates). В первом случае на поверхность полупроводниковой структуры наносятся два металлических затвора Шоттки, расстояние между которыми в самом узком месте $\sim 1$ мкм. При подаче на затворы отрицательного напряжения под ними формируются обедненные области, разделенные проводящим каналом, параметры которого определяются величиной приложенного отрицательного напряжения [4]. В транзисторе с боковыми управляющими электродами [5] проводящий канал и затворы, лежащие с ним в одной плоскости, формируются из двумерного электронного газа путем создания разделяющих их узких изолирующих областей шириной $0.1-0.5$ мкм. Такие же области могут изолировать друг от друга отдельные части многосекционных затворов. То, что проводящий канал и затворы расположены в одной плоскости, уменьшает экранирующее влияние затворов на межэлектронное взаимодействие в канале и обусловленные этим взаимодействием эффекты накопления заряда в квантовом проводе и образование спиновой поляризации. Изолирующие области могут быть созданы как в виде канавок, полученных путем химического, ионно-плазменного или плазмо-химического травления, так и путем локального анодного окисления (ЛАО) поверхности исходной гетероструктуры с помощью сканирующего зондового микроскопа (СЗМ). Для того чтобы транспорт электронов в канале был баллистическим, длина канала должна быть меньше длины свободного пробега двумерных электронов, которая для используемых нами структур при $4.2 \mathrm{~K}$ составляет 3-5 мкм. 
Создание структур с длиной канала $\leq 1$ мкм, имеющих по три управляющих боковых затвора с каждой стороны, требует применения литографии с характерными размерами элементов $\sim 0.1$ мкм. Это возможно с использованием электронной литографии высокого разрешения, как это делалось, например, в [4-6], или литографии с использованием атомно-силового микроскопа, например, путем ЛАО [7,8]. В последнем случае (особенно при глубине залегания двумерного электронного газа $\sim 60$ нм и более) не удавалось получить пробивные напряжения между электродами структуры более $350-500 \mathrm{MB}$, что недостаточно для уверенного управления проводимостью канала. К тому же в окисленных областях может накапливаться локализованный заряд, влияющий неконтролируемым образом на проводимость канала и распределение потенциала вдоль него. В связи с этим при изготовлении экспериментальных структур была применена специально разработанная методика импульсной силовой нанолитографии (ИСНЛ) [9], выполняемой на атомно-силовом микроскопе, оснащенном зондом с алмазной иглой. Данная технология позволяет делать узкие и глубокие разрезы в пленках полупроводников, обеспечивая создание структур с характерными размерами 20-100 нм. Метод ИСНЛ и его возможные применения подробно рассмотрены в работе [9], поэтому здесь укажем лишь его основные особенности.

Стандартным методом механической обработки поверхности с помощью атомно-силового микроскопа (ACM) является процарапывание канавок иглой АCM, прижатой к поверхности образца. Применительно к твердым материалам данная операция выполняется чаще всего с помощью жесткого стального кантилевера с алмазной пирамидой, имеющей относительно большой (30-50 нм) радиус кривизны острия. В ряде работ также применялись кремниевые зонды с алмазоподобным покрытием. Наличие покрытия уменьшает остроту иглы, что ухудшает пространственное разрешение литографии. Нами был предложен метод импульсной силовой нанолитографии (ИСНЛ), позволяющий использовать для механической обработки твердых материалов зонды с чрезвычайно тонкими и острыми (радиус кривизны острия порядка 10 нм) монокристаллическими алмазными иглами. Работа с подобным инструментом предполагает разработку специальных методов нанолитографии. Острую алмазную иглу можно глубоко воткнуть практически в любой материал при приложении силы вдоль ее оси, однако латеральный сдвиг иглы, находящейся под нагрузкой, приведет к ее повреждению. Царапать поверхность таким инструментом неэффективно. Предлагаемый метод основан на быстрой поточечной индентации (прокалывании) при малом (5-20 нм) расстоянии между соседними точками. Важным преимуществом данного метода является возможность получения канавок с отношением $R$ глубины к ширине порядка 1 в отличие от $R=0.1-0.3$, достижимых традиционными методами [9].

Исследуемые образцы изготавливались на основе гетероструктур GaAs/AlGaAs, выращенных в ИФП СО

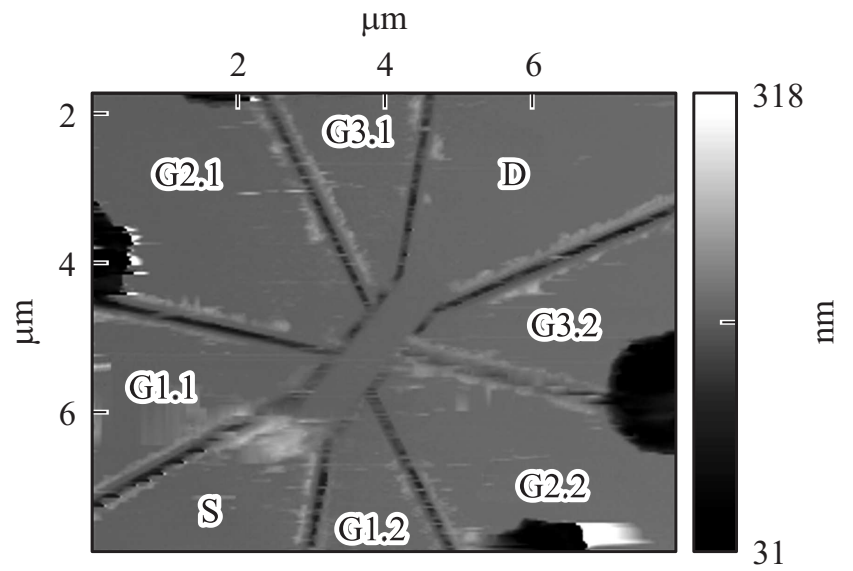

Рис. 1. СЗМ изображение структуры с шестью боковыми затворами.

PAН на подложке из полуизолирующего GaAs методом молекулярно-пучковой эпитаксии. Последовательно наращивались слои нелегированного GaAs толщиной 1 мкм, AlGaAs - 100 нм и защитный слой нелегированного GaAs - 35 нм. Слой $\mathrm{AlGaAs}$ содержит два $\delta$-слоя, легированных $\mathrm{Si}$. Толщина спейсера (расстояние от гетерограницы, где в треугольной потенциальной яме в $\mathrm{GaAs}$ формируется двумерный электронный газ, до ближайшего $\delta$-слоя) равна 50 нм. Концентрация и подвижность электронов в двумерном слое при температуре $4.2 \mathrm{~K}$ составляют соответственно $3.5 \cdot 10^{11} \mathrm{~cm}^{-2}$ и $3.5 \cdot 10^{5} \mathrm{~cm}^{2} / \mathrm{B} \cdot \mathrm{c}$.

Изготовление образцов проводилось в два этапа, как это ранее делалось в работе [8].

На начальном этапе с помощью стандартной оптической литографии и химического травления на поверхности гетероструктуры формировалась мезаструктура высотой $\sim 150$ нм. Затем методом взрывной фотолитографии создавалась система $\mathrm{Ni} / \mathrm{Ge} / \mathrm{Au}$ омических контактов к областям стока, истока и затворов и потенциальные контакты, обеспечивающие измерение проводимости канала по четырехзондовой схеме. На заключительном этапе оптической литографии химическим травлением формировались канавки, разделяющие области структуры там, где ширина этих канавок не была критична. После этого структуры собирались в корпус.

На втором этапе методом ИСНЛ с помощью СЗМ на структуре создавались канавки, отделяющие секции затворов друг от друга и от канала.

Изображение структуры с шестью боковыми затворами, полученное с помощью сканирующего зондового микроскопа, показано на рис. 1. Темные области вблизи краев изображения - концы канавок, протравленных на этапе фотолитографии и химического травления. Буквами показаны обозначения электродов структуры, которые в дальнейшем используются в тексте: S исток, D - сток; G1.1, G1.2, G2.1, G2.2, G3.1, G3.2 затворы. В случае, когда при измерениях затворы с разных сторон канала включаются параллельно, т. е. на 

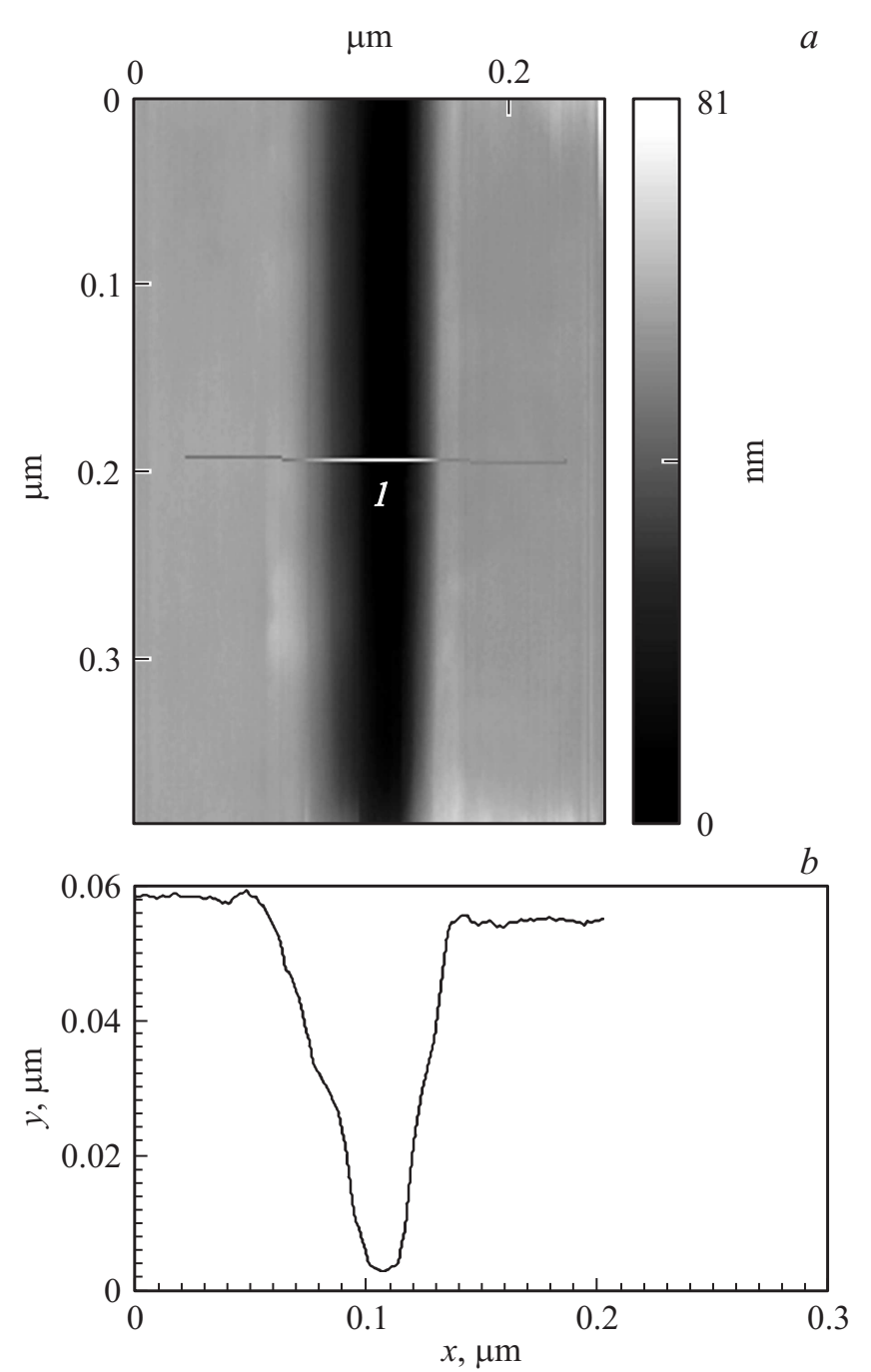

Рис. 2. СЗМ изображение отрезка канавки, созданной методом ИСН $(a)$, и профиль канавки по глубине $(b)$.

них подается одинаковое напряжение, пары обозначаются $\mathrm{G} 1, \mathrm{G} 2$ и $\mathrm{G} 3$ соответственно.

На рис. 2 представлены СЗМ изображение отрезка сформированной методом ИСНЛ канавки $(a)$ и измеренный профиль канавки по глубине $(b)$. Видно, что глубина канавки составляет порядка $60 \mathrm{HM}$, а ее ширина на половинной глубине $\sim 50$ нм $(R \approx 1.2)$. Измеренные токи утечек между электродами и каналом при температурах $1.5-10 \mathrm{~K}$ и напряжениях менее 1 В не превышали 100 пА, возрастая на несколько $(\sim 3)$ порядков при повышении температуры до 150-200 K.

Измерения характеристик структур проводились при температуре $1.5 \mathrm{~K}$. Методика измерений мало отличалась от описанной в работе [8]. Изготовленные структуры устанавливались в откачиваемую вставку, погружаемую в транспортный дьюар с жидким гелием. Зависимости дифференциальной проводимости канала $(G)$ от постоянных напряжений на затворах $\left(U_{\mathrm{Gi}}\right)$ измерялись на переменном сигнале частотой 133 Гц, амплитуда которого составляла 30-100 мкВ. Для измерения пе- ременного напряжения на потенциальных электродах стока и истока, как и тока истока, применялся метод синхронного детектирования. Постоянные напряжения измерялись непосредственно на электродах затворов.

Первоначально измерялись характеристики двухзатворной структуры, у которой методом ИСНЛ были созданы только канавки, отделяющие затворы от канала, а разделение затворов на секции не проводилось. На рис. 3 приведена зависимость от напряжения на затворах проводимости структуры и ее производной. Видно, что зависимость достаточно плавная и ее крутизна уменьшается вблизи значений $G_{0}$ и $2 G_{0}\left(G_{0}=2 e^{2} / h \approx 77\right.$ мкСм).

Вид зависимости проводимости канала от напряжения на затворах меняется для структуры с секционированными затворами. На рис. 4 показана такая зависимость, измеренная при параллельном включении всех затворов. Видно, что особенности на кривой возникают и при значениях проводимости канала, не кратных $G_{0}$. Кроме того, появляются области с гистерезисом при прямом и обратном направлении изменения напряжения на затворах.

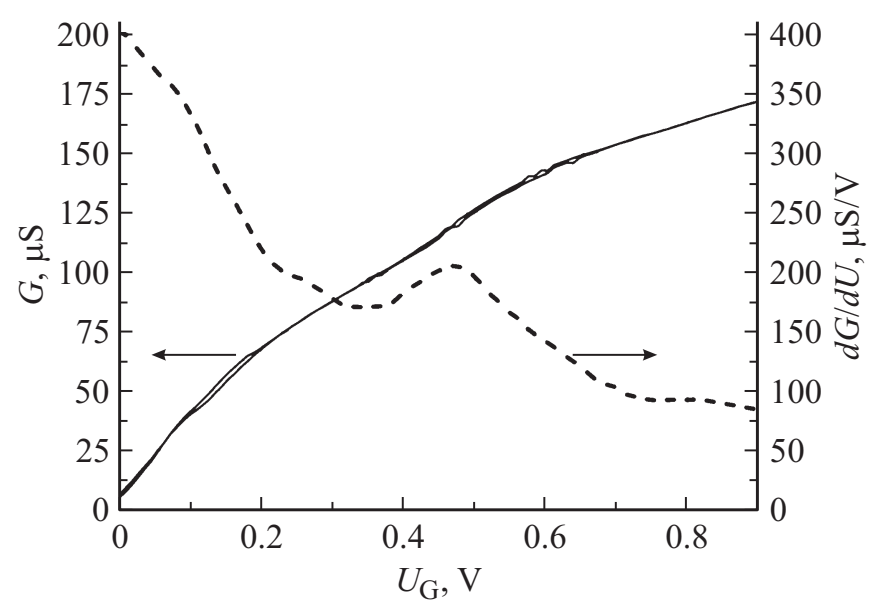

Рис. 3. Зависимость проводимости двухзатворной структуры от напряжения на затворах. Температура $T=1.5 \mathrm{~K}$.

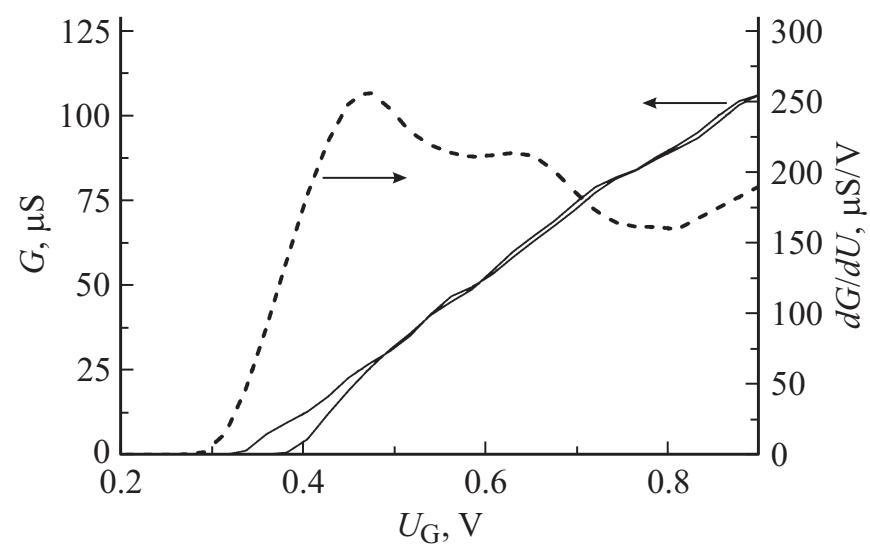

Рис. 4. Зависимость проводимости канала шестизатворной структуры от напряжения на затворах. Температура $T=1.5 \mathrm{~K}$. Напряжения на затворах $U_{\mathrm{G} 1}=U_{\mathrm{G} 2}=U_{\mathrm{G} 3}$. 


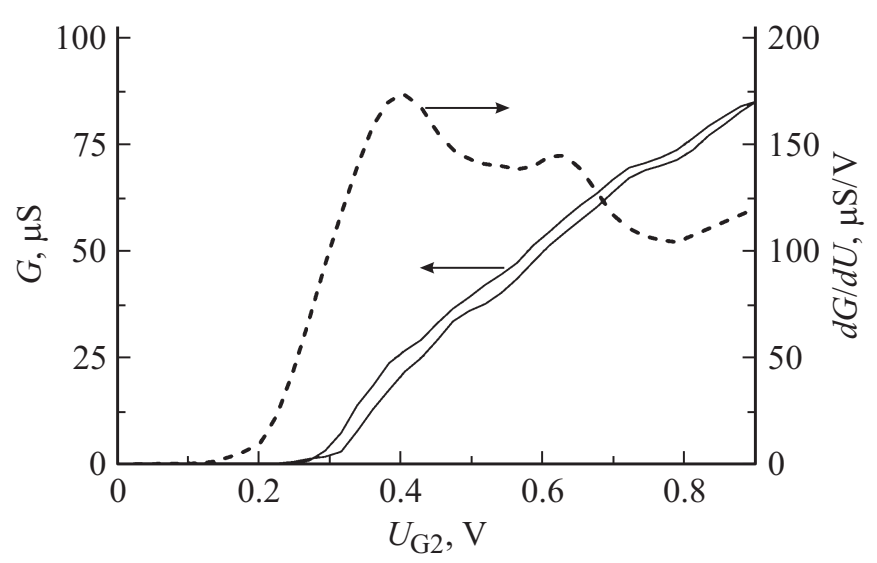

Рис. 5. Зависимость проводимости канала от напряжения на затворах G2. Температура $T=1.5 \mathrm{~K}$. Напряжения на затворах $U_{\mathrm{G} 1}=U_{\mathrm{G} 3}=0.7 \mathrm{~B}$.

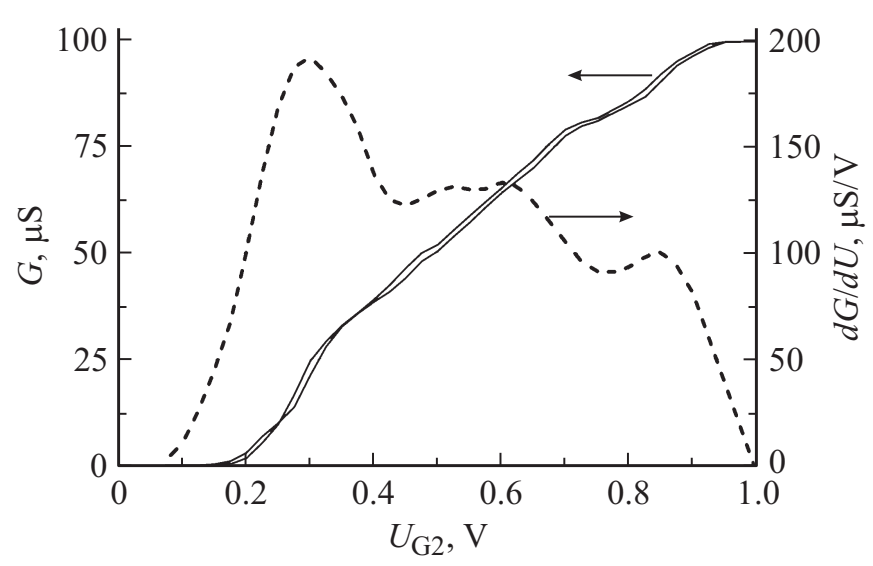

Рис. 6. Зависимость проводимости канала от напряжения на затворах G2. Температура $T=1.5 \mathrm{~K}$. Напряжения на затворах $U_{\mathrm{G} 1}=U_{\mathrm{G} 3}=0.8 \mathrm{~B}$.

Указанные особенности видны и на приведенных на рис. 5 и 6 зависимостях кондактанса от напряжения на затворах, измеренных при постоянных положительных напряжениях на затворах G1 и G3 и сканировании по напряжению на центральных затворах G2.

Обсуждение природы наблюдаемых особенностей требует проведения более подробных измерений, которые в настоящее время проводятся, и построения адекватной физической модели процессов в структуре. Однако приведенные результаты показывают, что применение развитого метода импульсной силовой нанолитографии с помощью СЗМ для создания изолирующих областей в полупроводниковых многозатворных структурах с квантовым каналом обеспечивает возможность управления продольным потенциальным рельефом канала. Метод позволяет создавать наноструктуры с планарными боковыми затворами в том числе и при использовании гетероструктур с большой (> 60 нм) глубиной залегания двумерного электронного газа. Возможность работы с отдельными кристаллами делает ИСНЛ эффективной в лабораторной практике при изготовлении наноструктур с оперативно изменяемой топологией.

Авторы благодарят В.А. Сабликова за интерес и внимание к работе и А.И. Торопова за предоставленные гетероструктуры $\mathrm{AlGaAs} / \mathrm{GaAs}$.

\section{Список литературы}

[1] C.W.J. Beenakker, van H. Houten. Sol. St. Phys., 44, 1 (1991).

[2] T. Morimoto, Y. Iwase, N. Aoki, T. Sasaki, Y. Ochiai, A. Shailos, J.P. Bird, M.P. Lilly, J.L. Reno, J.A. Simmons. Phys. Lett., 82 (22), 3952 (2003).

[3] A. Shailos, A. Ashok, J.P. Bird, R. Akis, D.K. Ferry, S.M. Goodnick, M.P. Lilly, J.L. Reno, J.A. Simmons. J. Phys.: Condens. Matter, 18, 1715 (2006).

[4] M. Pepper, C.G. Smith, R.J. Brown, D.A.Wharam, M.J. Kelly, R. Newbury, H. Ahmed, D.G. Hasko, D.C. Peacock, J.E.F. Frost, D.A. Ritchie, G.A.C. Jones. Semicond. Sci. Technol., 5, 1185 (1990)

[5] J. Nieder, A.D. Wieck, P. Grambow, H. Lage, D. Heitman, K.V. Klitzing, K. Ploog. Appl. Phys. Lett., 57 (25), 2695 (1990).

[6] В.И. Борисов, В.Г. Лапин, А.Г. Темирязев, А.И. Торопов, А.И. Чмиль. РЭ, 54 (4), 457 (2009).

[7] K. Matsumoto. Scanning Microscopy, 12 (1), 61 (1998).

[8] В.И. Борисов, В.Г. Лапин, В.Е. Сизов, А.Г. Темирязев. Письма ЖТФ, 37 (3), 85 (2011).

[9] A. Temiryazev. Diamond Relat. Mater., 48, 60 (2014).

Редактор А.Н. Смирнов

\section{Semiconductor Structures with One-Dimensional Quantum Channel and in-plane side gates fabricated with Pulse Force Nanolithography Method}

\author{
V.I. Borisov ${ }^{1}$, N.A. Kuvshinova ${ }^{1}$, S.P. Kurochka ${ }^{2}$, \\ V.E. Sizov ${ }^{1}$, M.V. Stepushkin ${ }^{1,2}$, A.G. Temiryazev ${ }^{1}$ \\ ${ }^{1}$ Kotel'nikov Institute \\ of Radio Engineering and Electronics \\ (Fryazino Branch), \\ Russian Academy of Sciences, \\ 141190 Fryazino, Moscow district, Russia \\ ${ }^{2}$ National University of Science and Technology \\ "MISIS“, \\ 119049 Moscow, Russia
}

Abstract Quasi-one-dimensional transistor structures with variable lateral potential profile have been created by impulse force nanolithography with the help of an atomic-force microscope. The structures were created on the bases of a $\mathrm{AlGaAs} / \mathrm{GaAs}$ heterostructure with a deep $(130 \mathrm{~nm}$ from the surface) bedding of the two-dimensional electron gas. The potential profile of the channel was formed by means of sectioned planar gates on both sides of the channel. The electric parameters of the structures, measured at temperatures as low as $1.5 \mathrm{~K}$, confirmed the effectiveness of the method for creating isolating regions with lateral sizes of approximately $10 \mathrm{~nm}$. 